\title{
Two new species of Cypricercinae McKenzie, 1971 (Crustacea: Ostracoda) from Thailand
}

\author{
Sukonthip SAVATENALINTON \\ Department of Biology, Faculty of Science, Mahasarakham University, \\ Maha Sarakham 44150, Thailand. \\ Email: sukonthip.s@msu.ac.th \\ urn:1sid:zoobank.org:author:254994A1-C8E1-4242-ADF8-184661366B2D
}

\begin{abstract}
Two new species of the subfamily Cypricercinae McKenzie, 1971 are described from the Western part of Thailand: Pseudostrandesia ratchaburiensis sp. nov. and Strandesia prachuapensis sp. nov. Pseudostrandesia ratchaburiensis sp. nov. is mainly characterized by a flange on the anteroventral part of the left valve (LV), a markedly large $\beta$ seta on the mandibular (Md) palp, serrated bristles on the third endite of the maxillula (Mx1), a slender caudal ramus (CR) with a long claw Ga (length ca half that of the ramus) and a relatively low number (13) of spiny whorls in the Zenker's organ. The discovery of both males and females of Pseudostrandesia ratchaburiensis sp. nov. in the present study constitutes the first report of a sexual population in this genus, thereby allowing for a comparison of the male reproductive organs (hemipenis and Zenker's organ) from a new species with those of other genera of Cypricercinae. Strandesia prachuapensis sp. nov. is most closely related to Strandesia odiosa (Moniez, 1892) and Strandesia flavescens Klie, 1932 as they bear similar anterior flanges on the right valve (RV). The key diagnostic features of the new Strandesia species are a large carapace (ca $1.5 \mathrm{~mm}$ ), an angulated antero-ventral part of the LV, a weak and small anterior inner list on the LV, an anterior flange on the RV, a markedly small aesthetasc $\mathrm{Y}$ on the second antenna, a large $\beta$ seta on the Md-palp, smooth bristles on the third endite of the Mx1 and a slender CR with a short claw Ga (length ca $1 / 3$ of the ramus). In addition, Pseudostrandesia complexa (Victor \& Fernando, 1981) comb. nov. is here proposed.
\end{abstract}

Keywords. Taxonomy, biodiversity, Southeast Asia, Strandesia, ostracods.

Savatenalinton S. 2021. Two new species of Cypricercinae McKenzie, 1971 (Crustacea: Ostracoda) from Thailand. European Journal of Taxonomy 733: 19-41. https://doi.org/10.5852/ejt.2021.733.1217

\section{Introduction}

The subfamily Cypricercinae McKenzie, 1971 presently consists of 11 genera (Meisch et al. 2019): Astenocypris G.W. Müller, 1912, Bradleycypris McKenzie, 1982, Bradleystrandesia Broodbakker, 1983, Bradleytriebella Savatenalinton \& Martens, 2009, Cypricercus Sars, 1895, Diaphanocypris Wurdig \& Pinto, 1990, Nealecypris Savatenalinton \& Martens, 2009, Pseudostrandesia Savatenalinton \& Martens, 2009, Spirocypris Sharpe, 1903, Strandesia Stuhlmann, 1888 and Tanycypris Triebel, 1959. The most diverse genus is Strandesia, with 97 species worldwide (Meisch et al. 2019). The key character of subfamily Cypricercinae is the presence of a Triebel's loop on the caudal ramus attachment while the 
generic characters are restricted to the valve morphology, e.g., a marginal groove along the ventral margin of the left valve, a number of inner lists, and also the soft parts, such as the structure of the caudal ramus and caudal ramus attachment, the presence/absence of a d-seta on the first thoracopod (T1) and the morphology of the hemipenis (Savatenalinton \& Martens 2009a, 2009b). In Thailand, Cypricercinae is the most diverse subfamily, which comprises 23 species in seven genera: Astenocypris, Bradleycypris, Bradleystrandesia, Bradleytriebella, Pseudostrandesia, Strandesia and Tanycypris (Savatenalinton \& Suttajit 2016; Savatenalinton 2017). Recently, three cypricercine species were described as new from the country: Strandesia martensi Savatenalinton, 2015, Strandesia pholpunthini Savatenalinton, 2015 and Tanycypris eugenkempfi Savatenalinton, 2017 (see Savatenalinton 2015, 2017). The two most diverse cypricercine genera in Thailand are Strandesia and Pseudostrandesia with eight and seven species, respectively. These two genera are close as they share several aspects, e.g., the morphology of the caudal ramus attachment and the hemipenis (see Savatenalinton \& Martens 2009b). One of the primary distinguishing characters is the occurrence of a d-seta on the T1 (present in Strandesia, absent in Pseudostrandesia). The biodiversity of non-marine ostracods in Thailand was studied in several parts of the country, mainly in the northern and northeastern parts, while other parts are still ill-investigated, such as the western part which comprises five provinces: Kanchanaburi, Tak, Prachuap Khiri Khan, Phetchaburi and Ratchaburi. The present contribution deals with two new species of Cypricercinae, which were found in the western part of Thailand.

\section{Material and methods}

Forty-five water bodies in the western part of Thailand were investigated in the years 2018-2019. Ostracod samples were taken with a hand net (mesh size $200 \mu \mathrm{m}$ ), instantly preserved in $70 \%$ ethanol. In the laboratory, specimens were sorted using a binocular microscope, soft parts were dissected in glycerine under a stereo microscope (Olympus SZ-PT) and later sealed on glass slides. Valves were stored dry in micropalaeontological slides. Soft parts were drawn using a camera lucida attached to a compound microscope. Carapaces and valves were observed and illustrated using a Scanning Electron Microscope (JEOL JSM6460LV - at the Faculty of Science, Mahasarakham University, Thailand). The chaetotaxy of the limbs follows the model proposed by Broodbakker \& Danielopol (1982), revised for the A2 by Martens (1987) and for the thoracopods by Meisch (2000). The classification of the Cypricercinae follows that proposed by Savatenalinton \& Martens (2009b). All type specimens are deposited in the Ostracod Collection in the Faculty of Science, Mahasarakham University, Maha Sarakham, Thailand.

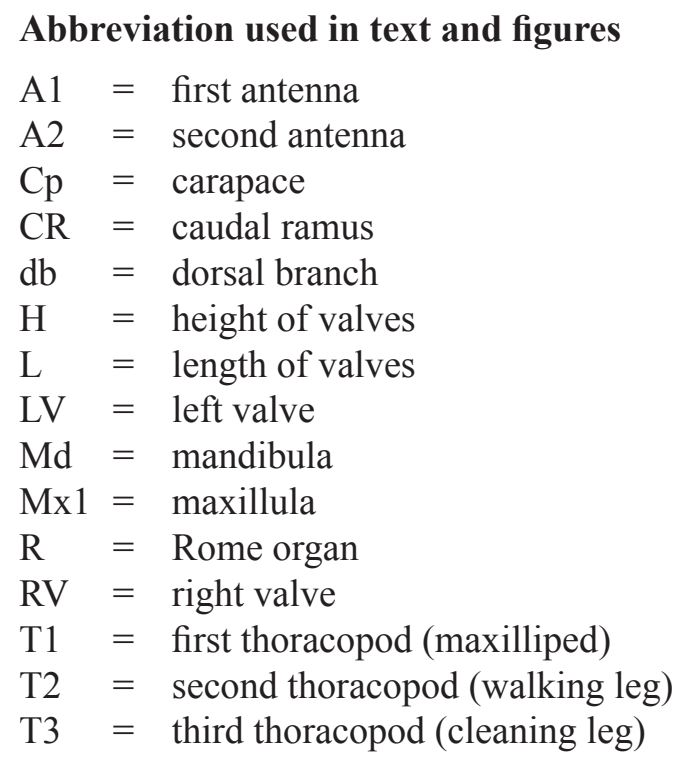


$\mathrm{vb}=$ ventral branch

$\mathrm{W}=$ width of carapace

\title{
Repositories
}

MSU $=$ Mahasarakham University, Maha Sarakham, Thailand

MSU-ZOC = Ostracod Collection of the Faculty of Science, Mahasarakham University, Maha Sarakham, Thailand

\section{Results}

\section{Taxonomic descriptions}

\author{
Class Ostracoda Latreille, 1802 \\ Subclass Podocopa G.O. Sars, 1866 \\ Order Podocopida G.O. Sars, 1866 \\ Suborder Cypridocopina G.O. Sars, 1866 \\ Superfamily Cypridoidea Baird, 1845 \\ Family Cyprididae Baird, 1845 \\ Subfamily Cypricercinae McKenzie, 1971 \\ Tribe Cypricercini McKenzie, 1971
}

Genus Pseudostrandesia Savatenalinton \& Martens, 2009

Pseudostrandesia ratchaburiensis sp. nov.

urn:Isid:zoobank.org:act:DB1E6F7C-8DB2-4093-9CF1-E081614BE8F6

Figs $1-6$

\section{Diagnosis}

$\mathrm{Cp}$ in lateral view elongated (length ca 2.2 times of height) with greatest height situated at one third of length, LV overlapping RV along all free margins, LV with flange on antero-ventral part and one anterior inner list, A1 seven-segmented, A2 with long natatory setae, undivided penultimate segment (in both females and males), Md-palp with long $\alpha$ seta and markedly large $\beta$ seta, two bristles on third endite of Mx1 serrated, T1 without d-seta, T2 with d1 seta longer (ca two times) than d2 seta, f-seta long (reaching far beyond tip of terminal segment), g-, h1 and h3 setae long (length ca $1 / 3$ of that of h2 claw), T3 with pincer organ, e- and f-setae long, CR slender, length of Ga ca half that of ramus, sa slightly longer than $\mathrm{Gp}$, sp thin and long (reaching tip of ramus), CR attachment stout, with Triebel's loop, situated at middle of distal part of main branch, $\mathrm{db}$ and vb well-developed, right palp of male $\mathrm{T} 1$ anteriorly with triangular lobe and two small apical triangular protrusions, hemipenis with medial shield broadly rounded, lateral shield elongated with blunt distal end, postlabyrinthal spermiduct curved, with 2 loops, Zenker's organ set with 13 spiny whorls, length ca 3.5 times the width.

\section{Differential diagnosis}

Pseudostrandesia ratchaburiensis sp. nov. is similar to P. complexa (Victor \& Fernando, 1981) and P. phetchabunensis Savatenalinton \& Martens, 2010. It differs from P. complexa by the more elongated $\mathrm{Cp}$ in the lateral view, the large $\beta$-seta on the Md-palp, the long g and h3 setae on the T2 and the morphology of the CR. It is obviously distinguishable from P. phetchabunensis by the presence of the antero-ventral flange of the LV.

\section{Etymology}

The species is named after Ratchaburi Province, where specimens of the new species were discovered. 


\section{Type material}

\section{Holotype}

THAILAND - Ratchaburi Province - $q$ (soft parts dissected in glycerine on a sealed glass slide and valves stored dry in a micropalaeontological slide); Huai Mahat Reservoir, Ban Kha District; $13^{\circ} 27.212^{\prime} \mathrm{N}, 9^{\circ} 27.721^{\prime} \mathrm{E}$; 20 Oct. 2018; MSU-ZOC.291.

\section{Allotype}

THAILAND - Ratchaburi Province • $\widehat{\jmath}$ (stored as the holotype); same collection data as for holotype; MSU-ZOC.298.

\section{Paratypes}

THAILAND - Ratchaburi Province $-3+9$ (stored as the holotype); same collection data as for holotype; MSU-ZOC.292 to $294 \cdot 3$ 우 ㅇ (carapaces stored dry in micropalaeontological slides); same

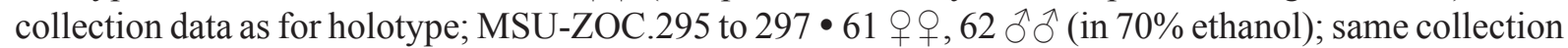
data as for holotype; MSU-ZOC.302 - 3 ổ (carapaces stored dry in micropalaeontological slides); same collection data as for holotype; MSU-ZOC.299 to 301.

\section{Type locality}

A total of 68 female specimens ( 1 holotype, 67 paratypes) and 66 male specimens ( 1 allotype, 65 paratypes) were collected at the type locality on 20 Oct. 2018. Accompanying ostracod fauna: Bradleycypris vittata (Sars, 1903), Bradleytriebella decorata (Sars, 1903), Dentocypria chantaranothaii Savatenalinton, 2017, Dentocypria sp., Pseudocypretta maculata Klie, 1932, Pseudostrandesia mamarilorum (Victor \& Fernando, 1981), Strandesia hornei Savatenalinton \& Martens, 2010, Strandesia kraepelini (Müller, 1906).

\section{Repository}

The holotype, allotype and all paratypes are deposited in the MSU-ZOC.

Measurements (in $\mu \mathrm{m}$ )

q: $\mathrm{Cp}(\mathrm{n}=3), \mathrm{L}=679-745, \mathrm{H}=318-321, \mathrm{~W}=329-336$; LV ( $=3), \mathrm{L}=729-745, \mathrm{H}=336-343$; RV $(\mathrm{n}=3), \mathrm{L}=721-737, \mathrm{H}=336-343$.

今.: Cp (n = 3), L = 650-691, H = 307-309, W = 293-295; LV ( $\mathrm{n}=2), \mathrm{L}=686-691, \mathrm{H}=307-309$; RV $(\mathrm{n}=2), \mathrm{L}=650-655, \mathrm{H}=304-306$.

\section{Description}

\section{Female}

CP IN LATERAL VIEW (Fig. 1A). Elongated (length ca 2.2 times of height), greatest height situated at one third of length, anterior margin rounded with flange on antero-ventral part of LV, posterior margin more narrowly rounded, $\mathrm{LV}$ overlapping $\mathrm{RV}$, especially antero-ventrally, valve surface set with short rim-pore setae.

Cp IN Dorsal VIEw (Fig. 1B). Subelliptical, with greatest width situated slightly behind mid-length, LV overlapping RV anteriorly and posteriorly, anterior and posterior extremities narrowly rounded.

LV IN INTERNAL VIEW (Fig. 1C, E-F). With groove along ventral margin, dorsal margin gently arched, greatest height situated at one third of length, sloping down to anterior and posterior margin, the former more widely rounded than the latter one, antero-ventral part with flange, ventral margin slightly sinuated 
around mid-length, calcified inner lamella relatively wide anteriorly, with one inner list, posteriorly narrower.

RV IN INTERNAL VIEW (Fig. 1D, G-I). With marginal selvage, calcified inner lamella without inner list, anteriorly broader than posteriorly.

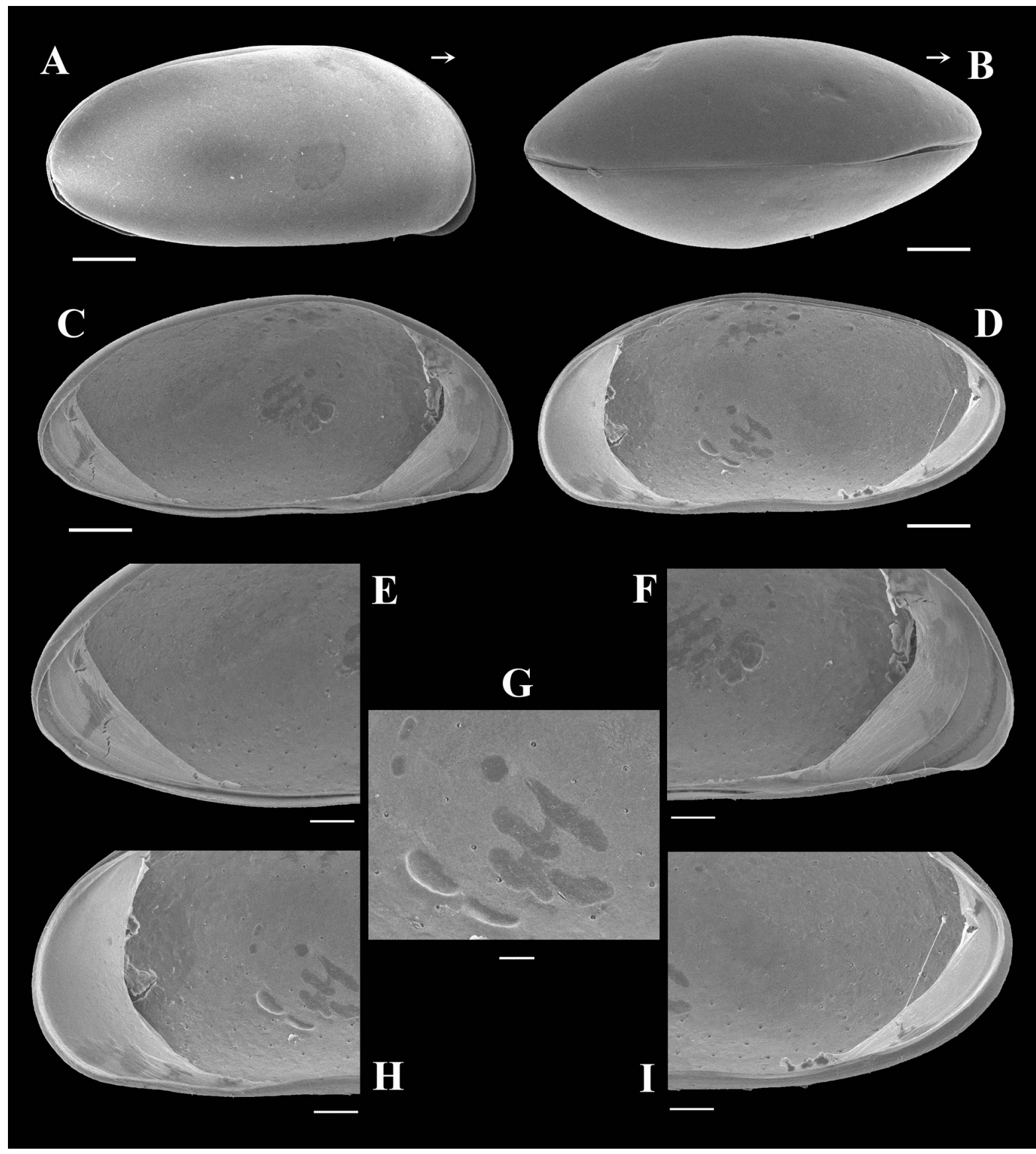

Fig. 1. Pseudostrandesia ratchaburiensis sp. nov., +. A. Paratype (MSU-ZOC.295). B. Paratype (MSU-ZOC.296). C-I. Holotype (MSU-ZOC.291). A. Cp, right lateral view. B. Cp, dorsal view. C. LV, internal view. D. RV, internal view. E. Posterior part of LV. F. Anterior part of LV. G. Muscle scars of RV. H. Anterior part of RV. I. Posterior part of RV. Scale bars: A-D = $100 \mu \mathrm{m}$; E-F, H-I $=50 \mu \mathrm{m} ; \mathrm{G}=$ $20 \mu \mathrm{m}$. Arrows point toward the anterior end. 
A1 (Fig. 3A). First segment with one short, dorso-subapical seta (reaching tip of segment) and two long ventro-apical setae. Second segment slightly wider than long, with one short dorso-apical seta (slightly beyond tip of segment) and long Rome organ. Third segment bearing two setae: one long dorso-apical seta, reaching halfway penultimate segment, and one short ventro-apical seta (reaching tip of next segment). Fourth segment with two long dorsal setae and two subequal, short ventral setae (the longer one reaching slightly beyond tip of next segment). Fifth segment dorsally with two long setae, ventrally with two (one long, one shorter) setae, the shorter one reaching halfway terminal segment. Penultimate segment with four long setae. Terminal segment with three (two long, one short) apical setae and an aesthetasc $\mathrm{y}_{\mathrm{a}}$, the latter ca $4 / 5$ of short apical seta.

A2 (Fig. 3B-C). Exopodite with three (one long, two short) setae, the long one reaching beyond tip of first endopodal segment. First endopodal segment with five long (reaching beyond tip of terminal claws) and one short natatory setae, length of the shortest seta less than half way penultimate segment, aesthetasc $\mathrm{Y}$ long, ventro-apical seta long, reaching beyond tip of terminal segment. Penultimate segment undivided, distally with three serrated claws G1-G3, aesthetasc y2 markedly long (reaching far beyond tip of terminal segment), z1-z3 setae long; this segment medially with two (one long, one shorter) dorsal setae (length of the short one ca $2 / 3$ of that of the long one) and four ventral setae of unequal length (t1-t4), t4 shortest seta (not reaching tip of segment). Terminal segment (Fig. 3C) with two serrated claws (GM and $\mathrm{Gm}$ ), g-seta and aesthetasc y3 with accompanying seta, length of Gm ca 3/4 of that of GM, length of aesthetasc y3 slightly more than half of that of accompanying seta, the latter slightly shorter than $\mathrm{Gm}$, length of seta $\mathrm{g} \mathrm{ca} 3 / 5$ of that of $\mathrm{Gm}$.

MD-PaLP (Fig. 3D). First segment with two large setae (S1 and S2), one slender, long seta and noticeably long, smooth $\alpha$-seta. Second segment dorsally with three unequal long apical setae, length of the shortest ca $1 / 4$ of that of the longest; ventrally with a group of three long hirsute setae, one shorter hirsute seta and

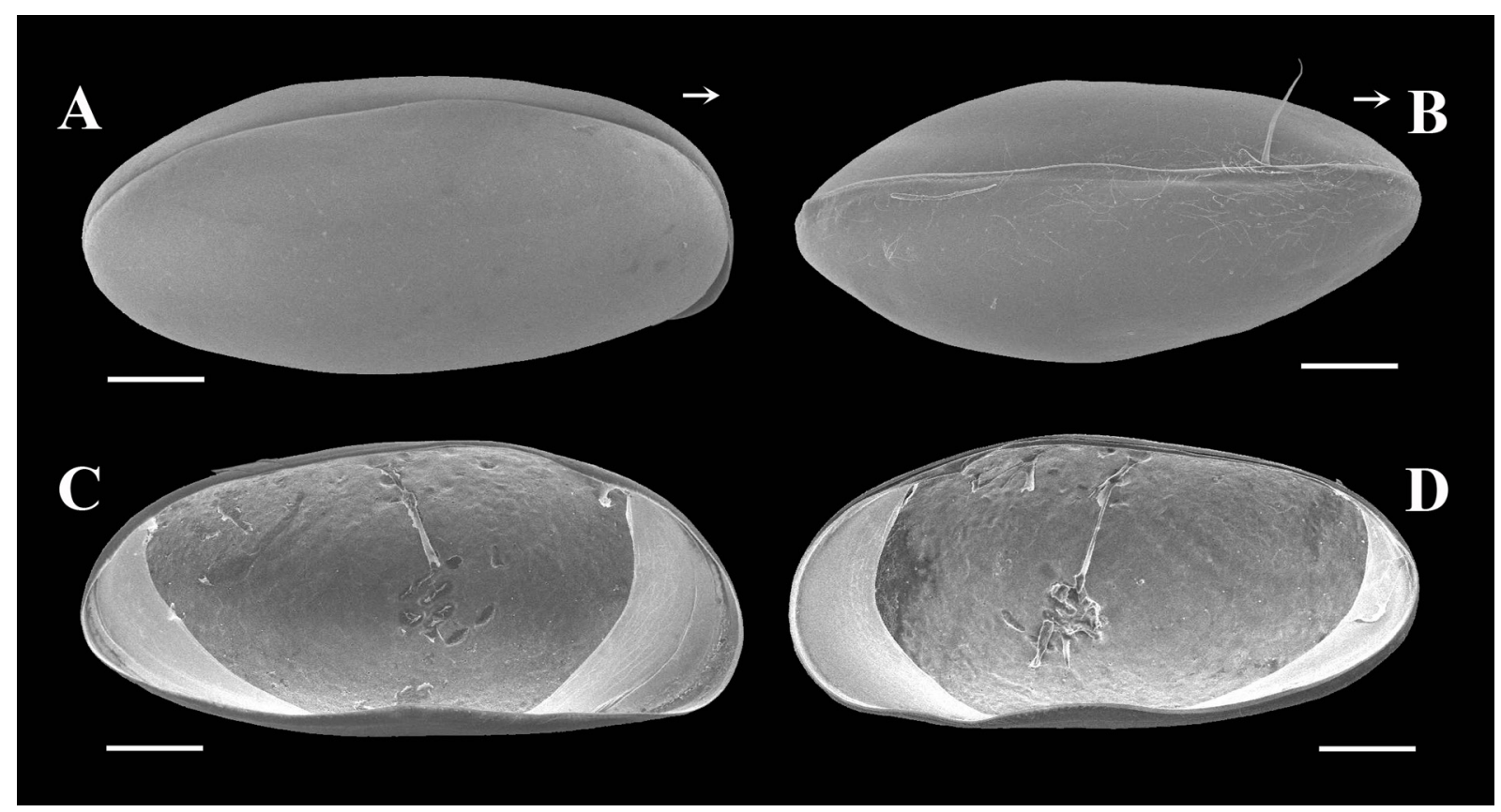

Fig. 2. Pseudostrandesia ratchaburiensis sp. nov., Ô. A. Paratype (MSU-ZOC.299). B. Paratype (MSUZOC.300). C-D. Allotype (MSU-ZOC.298). A. Cp, dorso-lateral view. B. Cp, slightly oblique ventral view. C. LV, internal view. D. RV, internal view (idem). Arrows point toward the anterior end. Scale bars: $100 \mu \mathrm{m}$. 


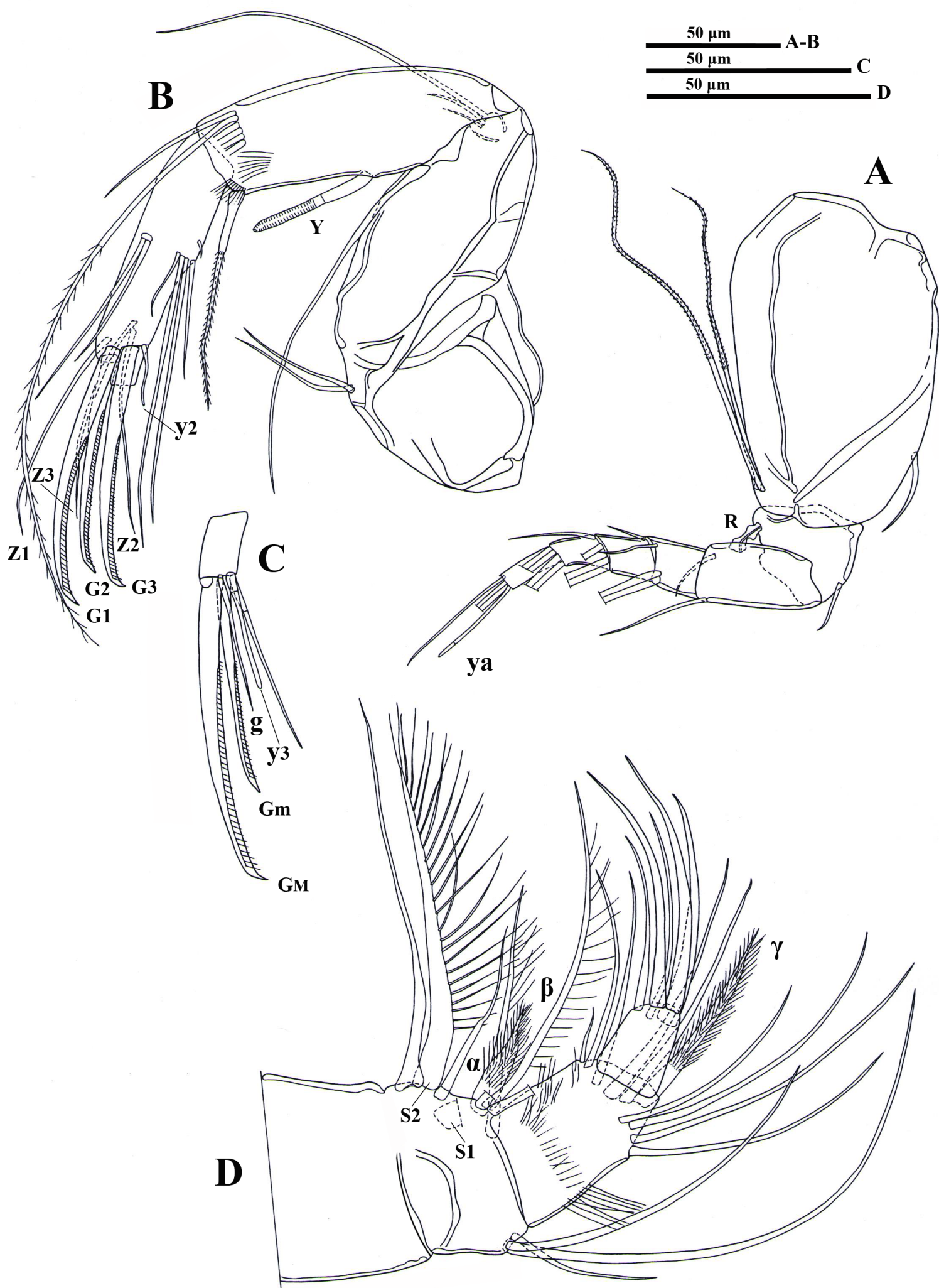

Fig. 3. Pseudostrandesia ratchaburiensis sp. nov. Paratype, + (MSU-ZOC.292). A. A1. B. A2. C. Terminal segment of A2. D. Md-palp. R-Rome organ. 


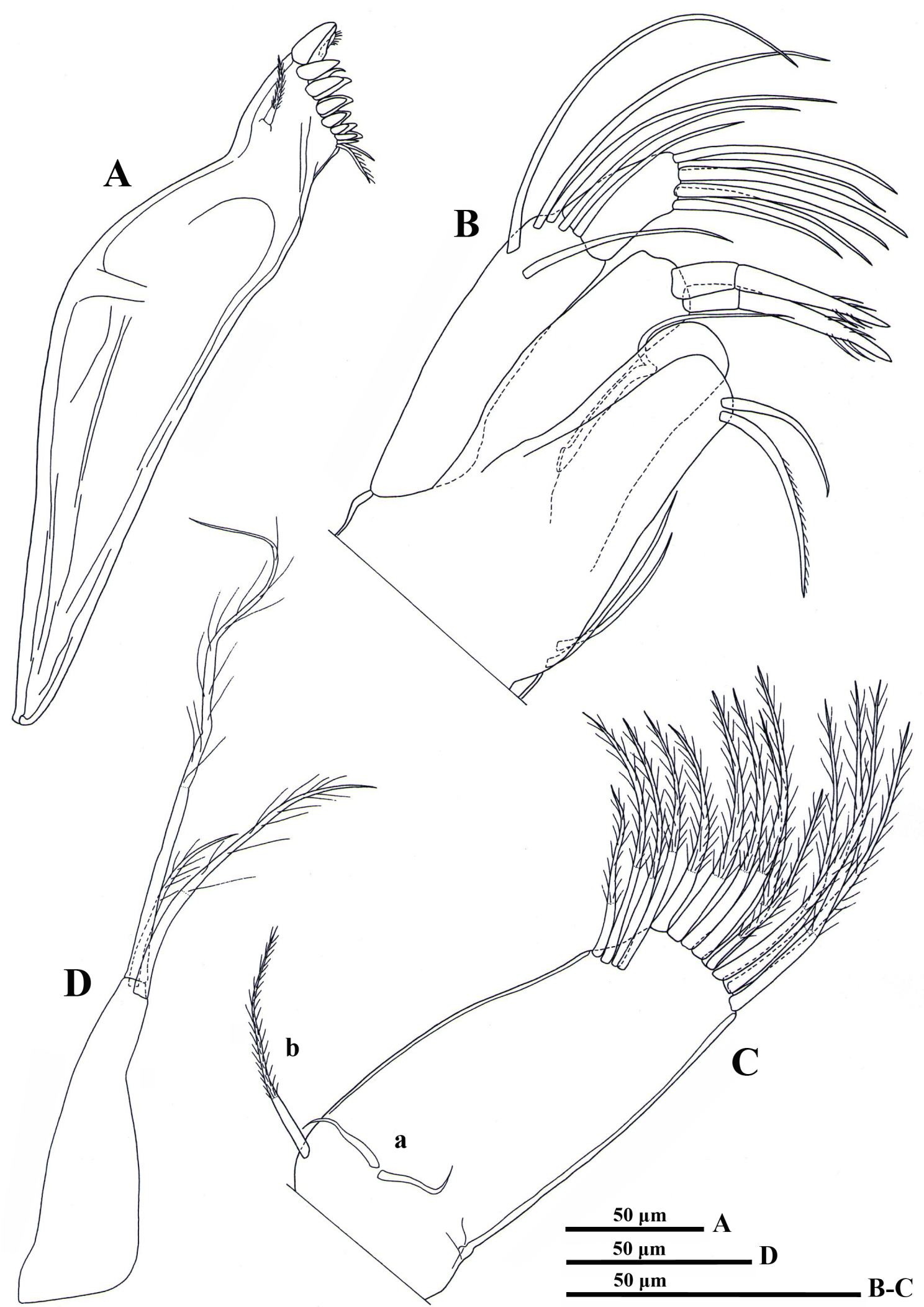

Fig. 4. Pseudostrandesia ratchaburiensis sp. nov. Paratype, $q$ (MSU-ZOC. 292). A. Md-coxa. B. Mx1. C. A part of basal protopod with medial endite of T1. D. T1-palp. 


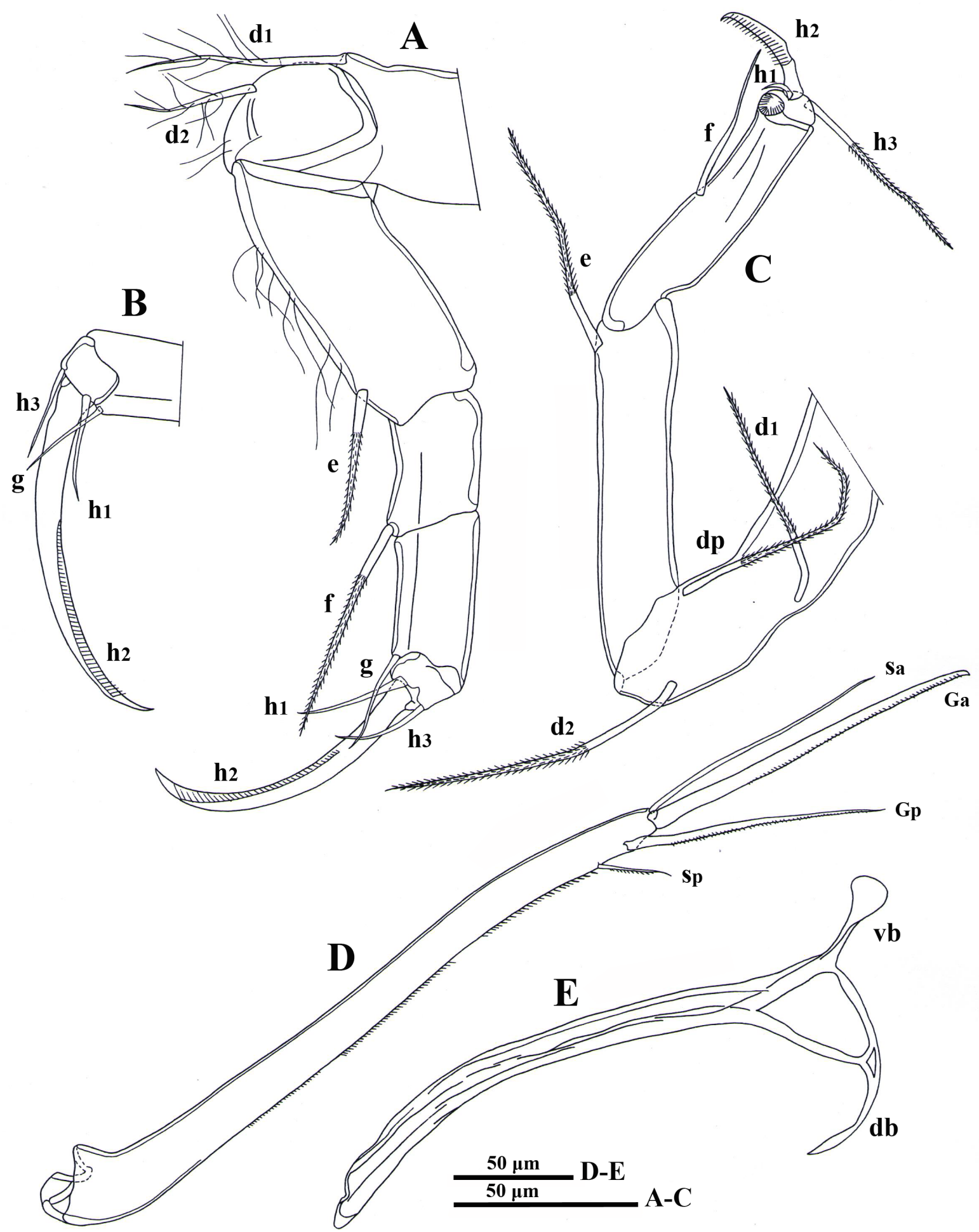

Fig. 5. Pseudostrandesia ratchaburiensis sp. nov. Paratype, $q$ (MSU-ZOC. 292). A. T2. B. Distal part of T2. C. T3. D. CR. E. CR attachment. 
markedly large $\beta$-seta (length ca $5 / 6$ of that of penultimate segment), the latter plumose, cone-shaped and with pointed tip. Penultimate segment bearing three groups of setae: dorsally with a group of four unequal, long, subapical setae; laterally with apical $\gamma$-seta and three further apical setae, the former stout, hirsute, long (length ca 2 times that of terminal segment); ventrally with two (one long, one short) apical setae, the latter reaching slightly beyond mid length of terminal segment). Terminal segment bearing three claws and two setae.

MD-COXA (Fig. 4A). Elongated, distally set with rows of teeth (large dorsally and smaller ventrally) and small setae, and with one dorso-subapical seta situated close to palp.

Mx1 (Fig. 4B). With two-segmented palp, three endites and large branchial plate; basal segment of palp with a group of four long, unequal apical setae and two (one long, one shorter) subapical setae, the latter reaching beyond tip of terminal segment, terminal segment elongated (length ca twice as long as width), apically with three claws and three setae. Two large bristles on third endite serrated apically. Sidewaysdirected bristles on first endite unequally long, length of short one ca $2 / 3$ of that of long one.

T1. Protopodite (Fig. 4C) with two short a-setae and long b-seta, distally with 14 (10 apical, four subapical) hirsute setae of unequal length. Endopodite (Fig. 4D) a weakly built palp, slender shape, with three unequal apical setae.

T2 (Fig. 5A-B). With seta d1 ca twice the length of seta d2. Second segment with short e-seta (reaching mid-length of penultimate segment). Penultimate segment divided, proximal segment bearing long f-seta (reaching far beyond tip of terminal segment), distal segment with long g-seta (almost the same length as h1 seta). Terminal segment with two (one dorsally, one ventrally) apical h1 and h3 setae and serrated claw (h2), length of h1 seta ca $1 / 3$ of that of h2 claw, h3 seta slightly shorter than h1 seta.

T3 (Fig. 5C). A cleaning limb. First segment with long d1, d2, dp setae. Second segment with long apical e-seta (extending slightly beyond half of the next segment). Third segment with medially long f-seta (reaching beyond tip of segment). Terminal segment with an apical pincer and three setae, one short h1 seta, one claw-like h2 seta and one reflexed subapical h3 seta, length of the latter ca $2 / 3$ of that of third segment.

CR (Fig. 5D). Slender, ventral margin of ramus with tiny setules, Ga and Gp long, serrated, length of Ga ca half of ramus, length of Gp ca $2 / 3$ that of Ga. sa long (slightly longer than Gp), sp thin and long (reaching tip of ramus).

CR ATtachment (Fig. 5E). Stout, with Triebel's loop situated at middle of distal part of main branch, db and vb well-developed, vb with swollen end.

\section{Male}

Carapace and valves as in female, although somewhat smaller (Fig. 2). All limbs as in female, except for last two segments of A2, T1 and reproductive organs (Fig. 6); penultimate segment of A2 with clawlike z1 and z2 setae, considerably reduced claw G1 and with claw G3 reduced to seta (Fig. 6A); T1endopodites forming asymmetrical prehensile palps; right palp (Fig. 6B) anteriorly with triangular lobe and two small apical triangular protrusions; left palp (Fig. 6C) anteriorly with elongated, curved lobe, two apical spines and few tubercles.

Hemipenis (Fig. 6D) with medial shield rounded, lateral shield elongated with blunt distal end. Postlabyrinthal spermiduct curved, with 2 loops. Zenker's organ (Fig. 6E) set with 13 spiny whorls, length about 3.5 times the width, distal end plate forming a crown of petal-like structures. 


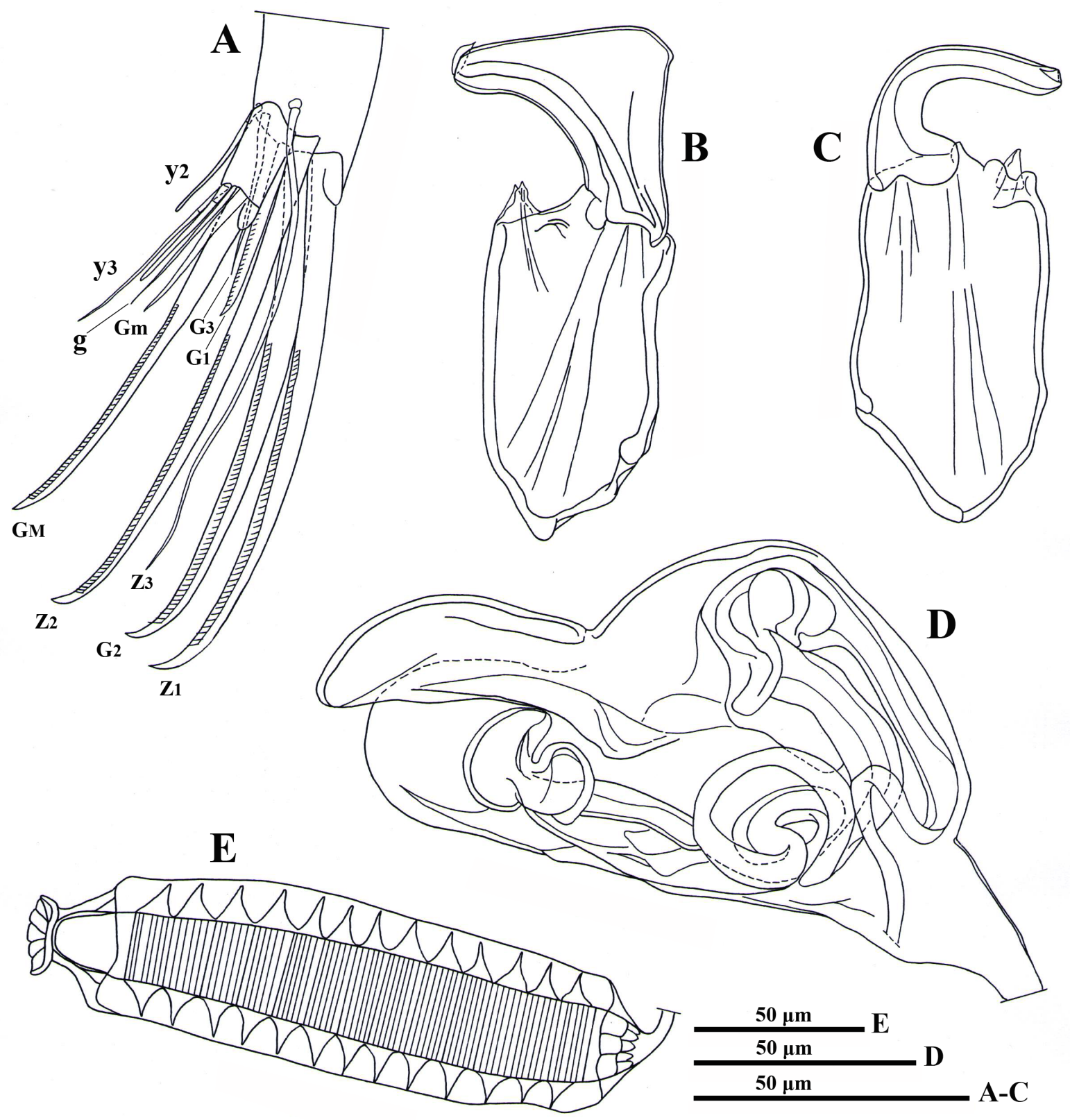

Fig. 6. Pseudostrandesia ratchaburiensis sp. nov. Allotype, o (MSU-ZOC.298). A. Distal end of penultimate segment and terminal segment of A2. B. Right prehensile palp. C. Left prehensile palp. D. Hemipenis. E. Zenker's organ.

Genus Strandesia Stuhlmann, 1888

Strandesia prachuapensis sp. nov. urn:1sid:zoobank.org:act:9F78C65D-157A-4E1C-9601-37399A71C764

Figs $7-10$

\section{Diagnosis}

Cp large (ca $1.5 \mathrm{~mm}$ ), elongated in lateral view (length ca 1.7 times of height), LV with angulated antero-ventral part, a weak and small anterior inner list situated on antero-ventral part, RV with anterior 
flange, not close to mouth region, A1 seven-segmented with small Rome organ, A2 with long natatory setae, aesthetasc Y markedly small (short and slender) with insertion situated ca one fourth of segment, $\beta$-seta on Md-palp large, two large bristles on third endite of Mx1 smooth, d-seta on T1 present, T2 with $\mathrm{d} 1$ and $\mathrm{d} 2$ setae (length of $\mathrm{d} 2$ seta less than half length of $\mathrm{d} 1$ seta), f-seta of intermediate length (not reaching tip of terminal segment), T3 with pincer organ, CR slender, claw Ga ca $1 / 3$ of ramus, claws $\mathrm{Ga}$ and $\mathrm{Gp}$ and ventral margin of ramus with tiny spine-like setules, sa seta slightly longer than claw $\mathrm{Gp}$, sp seta slender, reaching slightly beyond tip of ramus, CR attachment with Triebel's loop situated at middle of distal part of main branch.

\section{Differential diagnosis}

Strandesia prachuapensis sp. nov. resembles S. flavescens Klie, 1932 and S. odiosa (Moniez, 1892). It can be distinguished from them mainly by the narrower anterior flange on the RV, the size of the $\mathrm{Cp}$ (ca $1.5 \mathrm{~mm}$ ), the angulated antero-ventral part of the LV and the small and weak anterior inner list on the LV (for details of the differences, see the Discussion).

\section{Etymology}

The species is named after Prachuap Khiri Khan Province, which is also called in short 'Prachuap', where specimens of the new species were discovered.

\section{Type material}

\section{Holotype}

THAILAND - Prachuap Khiri Khan Province $\bullet+$ (soft parts dissected in glycerine on a sealed glass slide and valves stored dry in a micropalaeontological slide); Kui Buri District, rice field; $12^{\circ} 06.36^{\prime} \mathrm{N}$, 9948.42' E; 21 Oct. 2018; MSU-ZOC.303.

\section{Paratypes}

THAILAND - Prachuap Khiri Khan Province $\bullet 3+q$ (carapaces stored dry in micropalaeontological slides); same collection data as for holotype; MSU-ZOC.304 to 306.

\section{Type locality}

A total of 4 female specimens (1 holotype, 3 paratypes) were collected at the type locality on 21 Oct. 2018. Accompanying ostracod fauna: Cypretta sp., Cypris subglobosa Sowerby, 1840, Dentocypria aequiloba Savatenalinton, 2017, Hemicypris exigua Broodbakker, 1983, Hemicypris ovata Sars, 1903, Ilyocypris monstrifica (Norman, 1862), Notodromas sp., Pseudostrandesia mamarilorum, Stenocypris orientalis Victor \& Fernando, 1981.

\section{Repository}

The holotype and all paratypes are deposited in the MSU-ZOC.

Measurements (in $\mu \mathrm{m}$ )

Cp ( $\mathrm{n}=3), \mathrm{L}=1446-1483, \mathrm{H}=836-848, \mathrm{~W}=662-677$; LV ( $\mathrm{n}=1), \mathrm{L}=1483, \mathrm{H}=848 ; \mathrm{RV}(\mathrm{n}=2)$, $\mathrm{L}=1434, \mathrm{H}=800$.

\section{Description}

\section{Female}

C.. Large (ca $1.5 \mathrm{~mm}$ ), elongated in lateral view (Fig. 7A) (length ca 1.7 times height), anterior and posterior margins widely rounded, LV overlapping RV posteriorly and ventrally, dorsal margin gently arched, greatest height situated at mid-length, valve surface set with short rim-pore setae. 


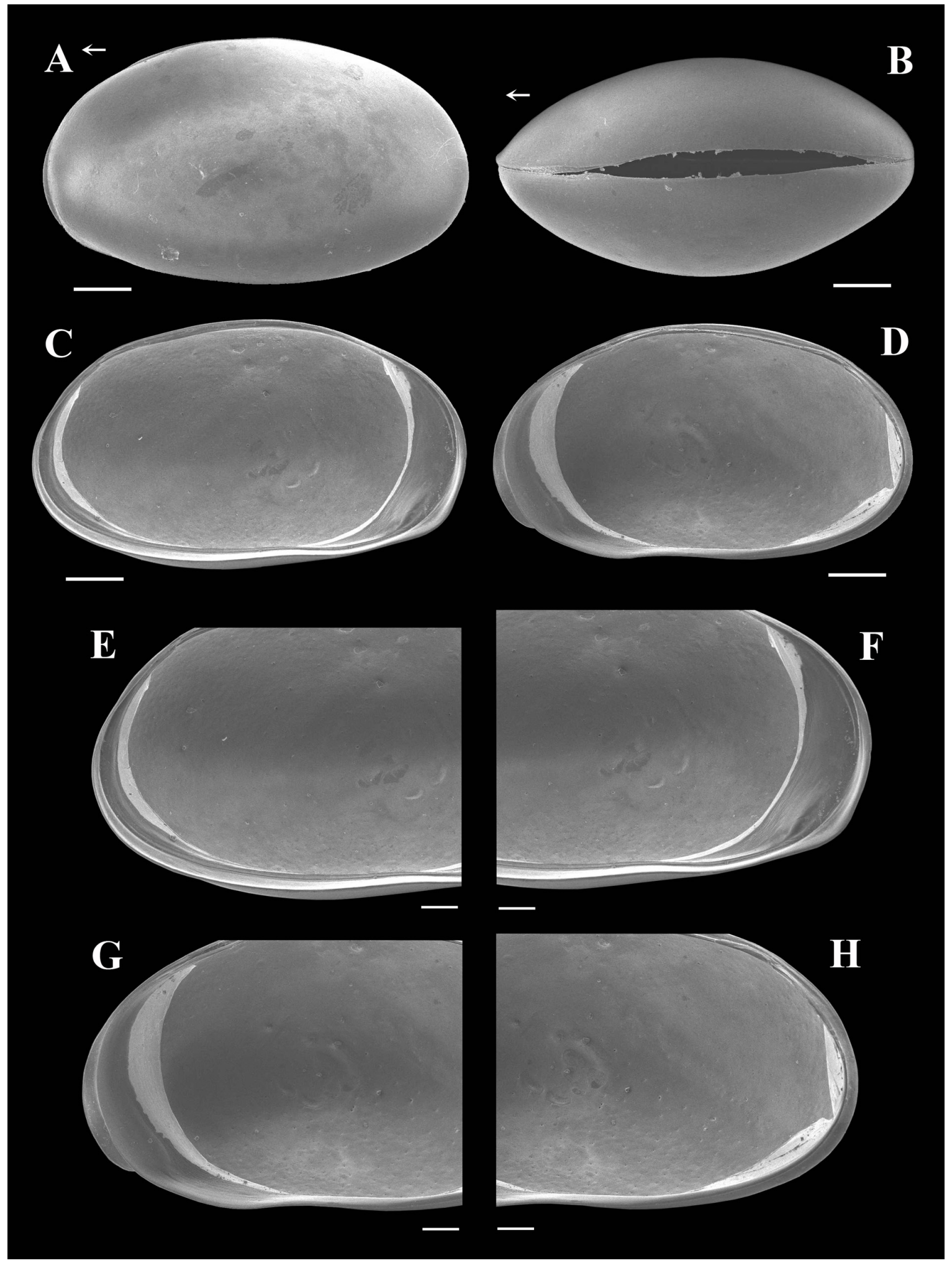

Fig. 7. Strandesia prachuapensis sp. nov., ․ A. Paratype (MSU-ZOC.304). B. Paratype (MSUZOC.305). C-H. Holotype (MSU-ZOC.303). A. Cp, left lateral view. B. Cp, dorsal view. C. LV, internal view. D. RV, internal view. E. Posterior part of LV. F. Anterior part of LV. G. Anterior part of RV. H. Posterior part of RV (idem). Scale bars: A-D $=200 \mu \mathrm{m} ; \mathrm{E}-\mathrm{H}=100 \mu \mathrm{m}$. Arrows point toward the anterior end. 
CP IN DORSAL VIEW (Fig. 7B). Subelliptical, with greatest width situated at mid-length, anterior margin of RV slightly protruded than LV.

LV IN INTERNAL VIEW (Fig. 7C, E-F). With groove along valve margin, dorsal margin arched, greatest height situated slightly in front of mid-length; sloping down to anterior and posterior margin, the former widely rounded, the latter slightly less widely rounded, antero-ventral part angulated, ventral margin slightly sinuated at mid-length; calcified inner lamella relatively wide anteriorly, with a weak and small inner list situated on antero-ventral part, posteriorly narrower.

RV IN INTERNAL VIEW (Fig. 7D, G-H). With inwardly displaced selvage and anterior flange, the latter not close to mouth region, calcified inner lamella without inner list, anteriorly broader than posteriorly.

A1 (Fig. 8A-A'). First segment with one dorso-subapical seta of intermediate length (almost reaching tip of segment) and two long ventro-apical setae, Wouters organ absent. Second segment slightly wider than long, with one markedly short dorso-apical seta (reaching tip of segment) and small Rome organ. Third segment bearing two (one dorso-apical and one ventro-apical) setae of intermediate length, both reaching slightly beyond tip of next segment. Fourth segment with two long dorsal setae and two subequal, shorter ventral setae (the short one not reaching tip of next segment, the longer one reaching slightly beyond tip of next segment). Fifth segment dorsally with two long setae, ventrally with two (one long, one shorter) setae, the shorter one reaching beyond tip of terminal segment. Penultimate segment with four long setae. Terminal segment with three (two long, one short) apical setae and aesthetasc $y_{a}$, the latter markedly long (ca 1.7 times that of short apical seta).

A2 (Fig. 8B). Exopodite with three (one long, two short) setae, the long one reaching beyond tip of first endopodal segment. First endopodal segment with five long (reaching tip of terminal claws) and one short natatory setae, length of the shortest seta reaching half way the penultimate segment, aesthetasc $\mathrm{Y}$ small (short and slender), insertion situated ca $1 / 4$ of segment, ventro-apical seta long, reaching slightly beyond tip of penultimate segment. Penultimate segment undivided, distally with three serrated claws G1-G3, aesthetasc y2 short (not reaching tip of terminal segment), z1-z3 setae long; this segment medially with two (one long, one shorter) dorsal setae (length of the short one ca $3 / 4$ of that of the long one) and four ventral setae of unequal length (t1-t4). Terminal segment with two serrated claws (GM and $\mathrm{Gm}$ ), g-seta and aesthetasc y3 with accompanying seta, length of $\mathrm{Gm} \mathrm{ca} 3 / 4$ of that of GM, length of aesthetasc $\mathrm{y} 3$ more than half of that of $\mathrm{Gm}$ and slightly shorter than accompanying seta, length of g-seta ca $3 / 4$ of aesthetasc $y 3$.

MD-COXA (Fig. 8C). Elongated, distally bearing rows of teeth (large dorsally and smaller ventrally) and small setae, and one dorso-subapical seta situated close to palp.

Md-PALP (Fig. 9A). First segment with two large setae (S1 and S2), one slender, long seta and long, smooth $\alpha$-seta. Second segment dorsally with three unequal long apical setae, length of the shortest seta less than half of that of the longest seta; ventrally with a group of three long hirsute setae, one shorter hirsute seta and large $\beta$-seta (length ca $3 / 4$ of that of penultimate segment), the latter large, plumose, cone-shaped and with pointed tip. Penultimate segment consisting of three groups of setae: dorsally with a group of four unequal, long, subapical setae; laterally with apical $\gamma$-seta and three further apical setae, the former stout, hirsute, long (length ca 1.5 times of that of terminal segment); ventrally with two (one long, one short) apical setae, the latter reaching $1 / 3$ of length of terminal segment. Terminal segment bearing three claws and two setae.

Mx1 (Fig. 9B). With two-segmented palp, three endites and large branchial plate; basal segment of palp with a group of five long, unequal apical setae and two (one long, one shorter) subapical setae, the latter reaching half way of terminal segment, terminal segment elongated, apically with three claws and three 


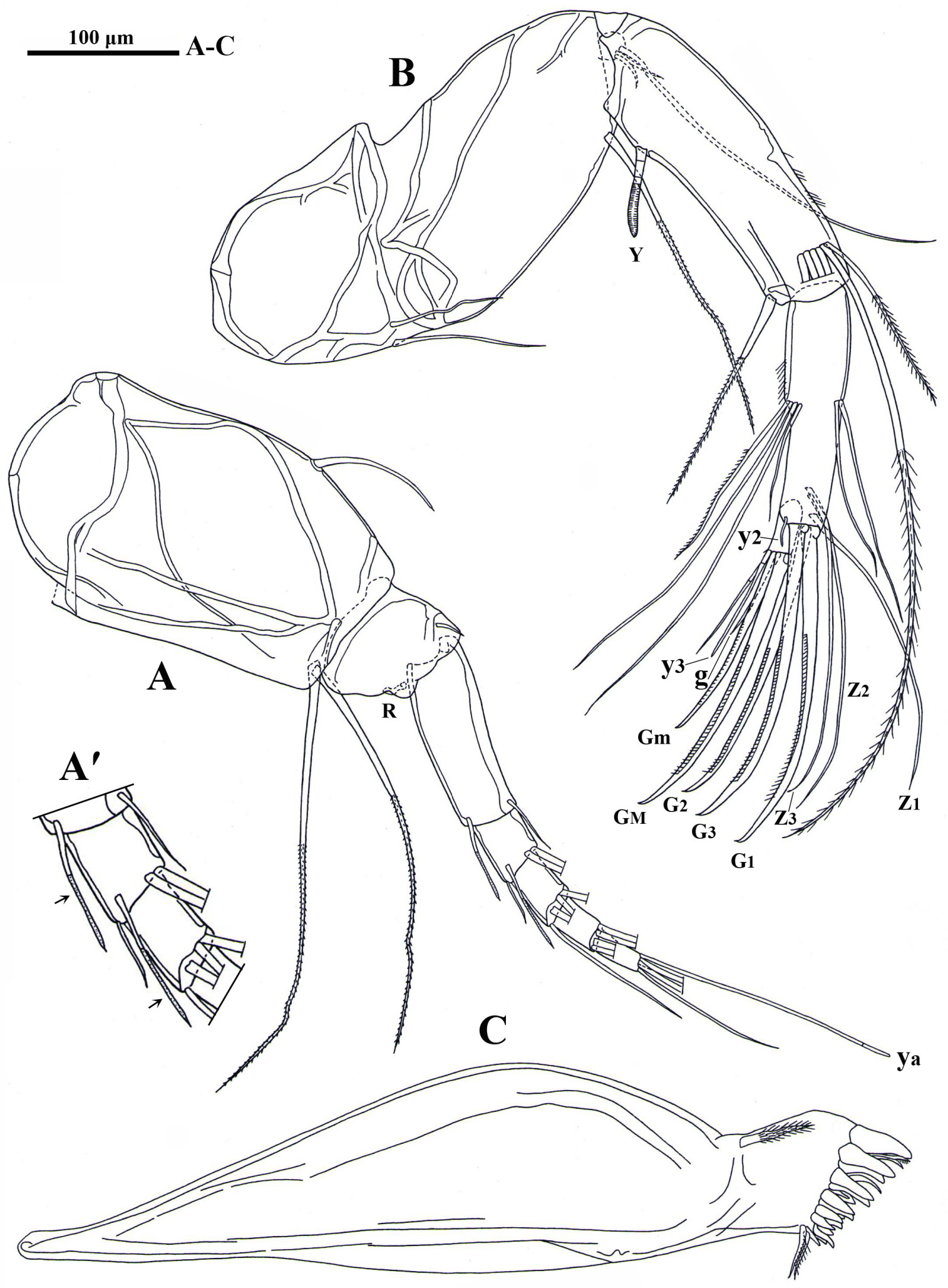

Fig. 8. Strandesia prachuapensis sp. nov. Holotype, $q$ (MSU-ZOC.303). A. A1. A'. Aesthetasc-like setae on third and fourth segments of A1. B. A2. C. Md-coxa. R-Rome organ. 


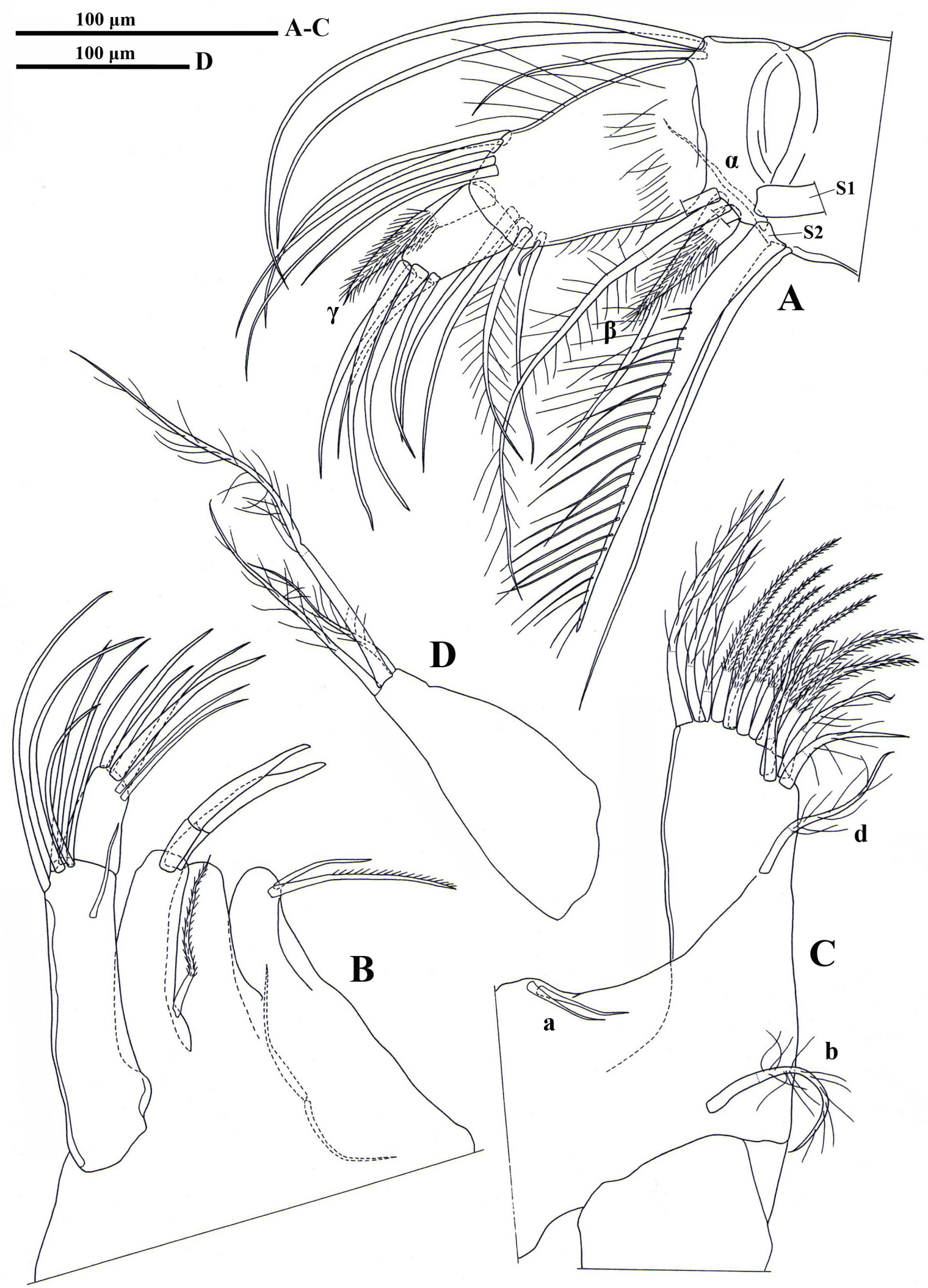

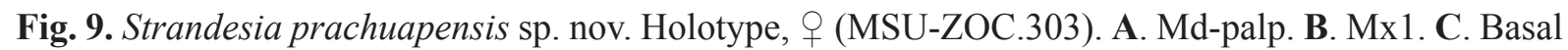
protopod with medial endite of T1. D. T1-palp. 


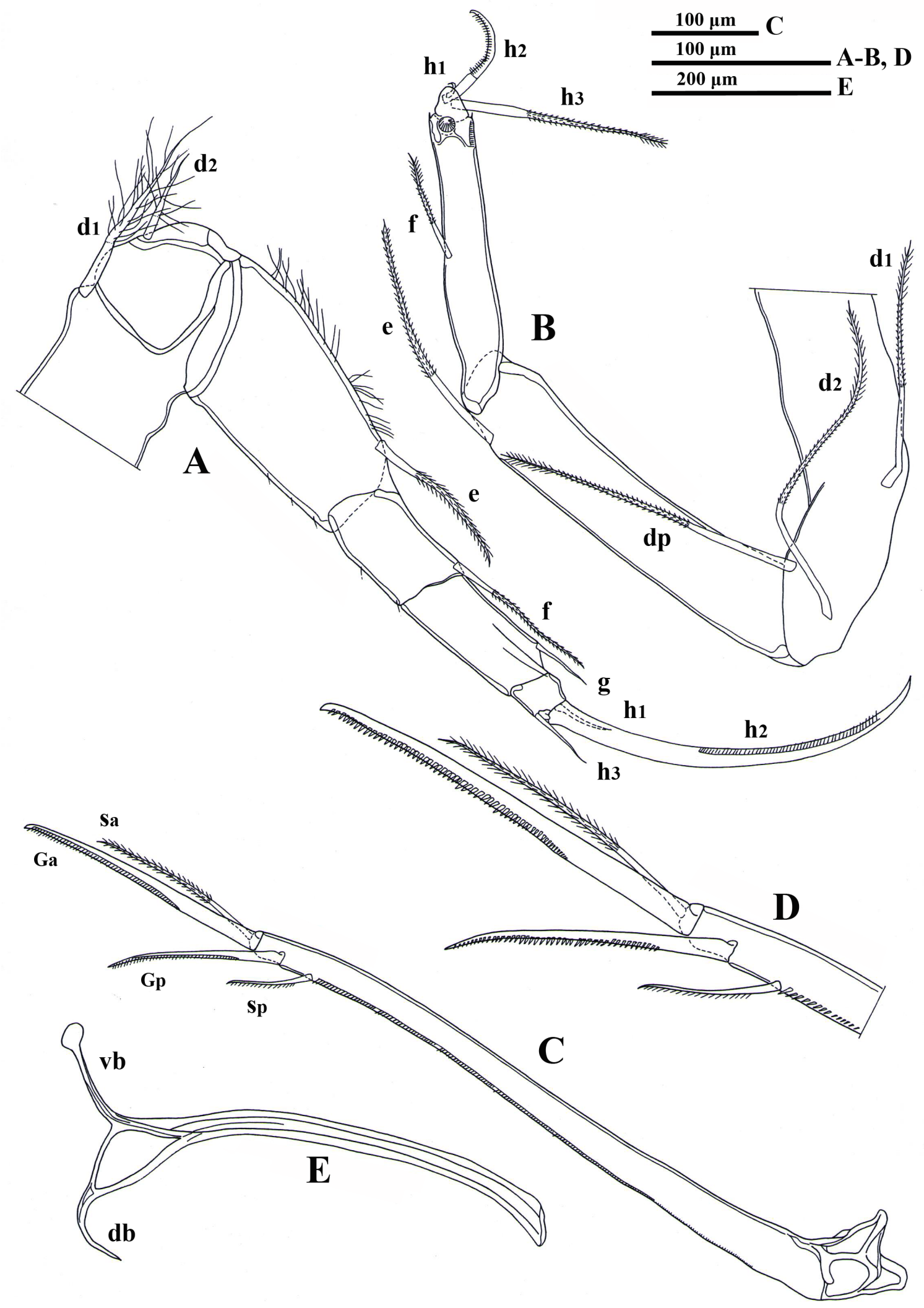

Fig. 10. Strandesia prachuapensis sp. nov. Holotype,, (MSU-ZOC.303). A. T2. B. T3. C. CR. D. Distal end of CR. E. CR attachment. 
setae. Two large bristles on third endite smooth. Sideways-directed bristles on first endite unequally long, length of short one ca half of that of long one.

T1 (Fig. 9C). Protopodite with two short a-setae, long b and d-setae, masticatory process distally with 14 (10 apical, four subapical) hirsute setae of unequal length. Endopodite a weakly built palp with three unequal apical setae.

T2 (Fig. 10A). With seta d1 more than twice the length of seta d2. Second segment with short e-seta (reaching slightly beyond mid-length of penultimate segment). Penultimate segment divided, proximal segment bearing f-seta of intermediate length (not reaching tip of terminal segment), distal segment with a short g-seta (reaching slightly beyond tip of terminal segment). Terminal segment with two (one dorsally, one ventrally) apical h1 and h3 setae and a serrated claw (h2), h1 and h3 setae subequal in length, length of claw $\mathrm{h} 2$ longer than that of penultimate segment.

T3 (Fig. 10B). A cleaning limb. First segment with long d1, d2, dp setae. Second segment with long

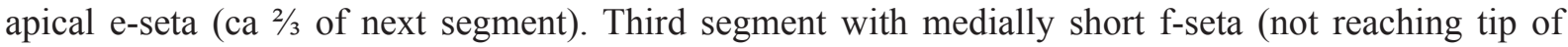
segment). Terminal segment with apical pincer and three setae, one short h1 seta, one claw-like h2 seta and one reflexed subapical h3 seta, length of the latter $\mathrm{ca}^{2} / 3$ of that of third segment.

CR (Fig. 10C-D). Slender, claws Ga and Gp weakly serrated, claw Ga short (ca 1/3 of ramus), length of claw Gp ca $3 / 5$ of that of claw Ga, sa seta slightly longer than claw Gp, sp seta slender, reaching slightly beyond tip of ramus, ventral margin of ramus with tiny setules.

CR ATtAChMENT (Fig. 10E). With Triebel's loop situated at middle of distal part of main branch, db and $\mathrm{vb}$ well-developed, vb with swollen end.

\section{Male \\ Unknown.}

\section{Key to Pseudostrandesia species}

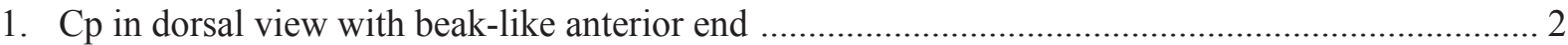

- $\quad \mathrm{Cp}$ in dorsal view without beak-like anterior end ...................................................................... 3

2. $\mathrm{Cp}$ in dorsal view with beak-like posterior end, penultimate segment of A2 not divided

- Cp in dorsal view with rounded posterior end, penultimate segment of A2 divided

3. Cp with large posterior LV overlap over RV, $\mathrm{Cp}$ in frontal view not oblique

- Cp without large posterior LV overlap over RV

4. LV with antero-ventral lip-like flange

- LV without antero-ventral flange

5. $\beta$-seat on Md-palp markedly large, $\mathrm{h} 3$ seta on $\mathrm{T} 2$ remarkably long ........ P. ratchaburiensis sp. nov.

- $\quad \beta$-seat on Md-palp small, h3 seta on T2 short ... P. complexa (Victor \& Fernando, 1981) comb. nov.

6. $\mathrm{Cp}$ in lateral view with narrow, bluntly pointed posterior end, very small overlap anteriorly

- $\quad \mathrm{Cp}$ in lateral view with rounded posterior end 
7. $\mathrm{Cp}$ in lateral view subovate, $\mathrm{LV}$ without anterior inner list

P. guleni Külköylüoğlu, Yavuzatmaca \& Y1lmaz, 2020

- Cp in lateral view elongated, LV with anterior inner list

8. Cp with large anterior overlap, Cp oblique in frontal view

- Cp with small anterior overlap

9. Cp in lateral view with greatest height situated at mid-length, one bristle on $M x 13^{\text {rd }}$ endite smooth and one serrated P. ovata Savatenalinton \& Martens, 2010

- Cp in lateral view with greatest height situated before mid-length, both bristles on Mx1 $3^{\text {rd }}$ endite serrated

P. petchabunensis Savatenalinton \& Martens, 2010

\section{Discussion}

\section{Pseudostrandesia}

One of the discriminating characters between the genera Strandesia and Pseudostrandesia is the occurrence of the d-seta on the T1, which is present in the former and absent in the latter genus (Savatenalinton \& Martens 2009b). The terminal part of the T1 protopodite (masticatory process) contains many setae which, in Cypricercinae, are divided into two groups: apical and subapical setae. The former group usually consists of 10 setae while about four setae belong to the latter (see Savatenalinton \& Martens 2009a, 2009b, 2010). Frequently, one of the subapical setae is erroneously indicated as a d-seta. For example, in Strandesia mamarilorum Victor \& Fernando, 1981, although the presence of T1 d-seta was mentioned in the description, no d-seta appeared in the original illustrations (see Victor \& Fernando 1981). The absence of the d-seta on the T1 in this species was confirmed by the redescription, and it was thus transferred to Pseudostrandesia (see Savatenalinton \& Martens 2010). A similar case probably occurs in Strandesia complexa Victor \& Fernando, 1981. Strandesia complexa was described based on material from the Philippines (Victor \& Fernando 1981), and it has not been reported again since its discovery, thus it remains an endemic species of the country. The redescription of $S$. complexa should confirm the presence/absence of the d-seta on the T1. However, based on the present information with regards, particularly, to its illustrations, the d-seta is absent on the T1 of $S$. complexa. Thus, here it is tentatively transferred to the genus Pseudostrandesia.

Pseudostrandesia ratchaburiensis sp. nov. described here resembles $P$. complexa in the presence of an antero-ventral flange of the LV and a similar sized Cp. However, the distinguishing characters are recognized in valves and the soft parts morphology. In the new species, the $\mathrm{Cp}$ is more elongated in the lateral view. The diagnostic features of the soft parts are clearly seen in the Md-palp, the T2 and the CR. The $\beta$-seta on the Md-palp is somewhat large in the new species, while it was small in P. complexa. The long $g$ and $\mathrm{h} 3$ setae of the $\mathrm{T} 2$ in the new species are also indicative aspects for discrimination between these two taxa. Moreover, the morphology of the CR shows several distinguishing aspects. The claw Ga is longer in Pseudostrandesia new species appearing half length of the ramus (less than half the length of the ramus in $P$. complexa). The sa seta is longer than the claw Gp in the new species, whereas it is shorter in $P$. complexa. In addition, the sp seta of the new species is also longer (slightly beyond the tip of the ramus), while it does not reach the tip of the ramus in $P$. complexa.

Apart from P. complexa, P. ratchaburiensis sp. nov. is similar to $P$. phetchabunensis, especially in the carapace shape in the lateral view, at first glance. The presence of the antero-ventral flange of the LV in the new species is clearly an indicative character to separate it from P. phetchabunensis. In addition, the differences between these two species are found in the soft parts morphology. Pseudostrandesia ratchaburiensis sp. nov. is distinguishable from $P$. phetchabunensis by, for example, the absence of the 
Wouters organ, the longer $\alpha$ - and the larger $\beta$-setae on the Md-palp, the longer h1 seta on the T2 and the longer claw $\mathrm{Ga}$ of the $\mathrm{CR}$.

All species of Pseudostrandesia are represented by parthenogenetic populations, except for $P$. ratchaburiensis sp. nov. The discovery of males and females of $P$. ratchaburiensis sp. nov. is the first report of a sexual population in this genus. This reveals that the hemipenis morphology of Pseudostrandesia sp. nov. conforms to the type C of the hemipenis proposed by Savatenalinton \& Martens (2009b), which is the character of Cypricercus and some Strandesia species resulting in the affinity among these three genera. However, the Zenker's organ of P. ratchaburiensis sp. nov. possesses a considerably smaller number of spiny whorls, ca 13, whereas it is ca 20-28 spiny whorls in Cypricercus, Strandesia (see Savatenalinton \& Martens 2009a) or even in other cypricercine genera, such as Bradleycypris (see Savatenalinton \& Martens 2010), Bradleystrandesia (see Savatenalinton \& Martens 2009b) and Tanycypris (see Savatenalinton 2014). The shorter Zenker's organ observed in Pseudostrandesia ratchaburiensis sp. nov. would reflect its smaller sperm size or potentiality of sperm transfer, as Zenker's organ is used for sperm pumping during copulation.

Currently, there are 10 species of Pseudostrandesia worldwide (Meisch et al. 2019; Külköylüoğlu et al. 2020; present study). Thus far, eight species, including the new species and new combination, have been reported merely from Southeast Asian countries, while the two remaining species (P. calapanensis and $P$. guleni) have also been recorded in the Palaearctic region. This implies that this lineage would originated from Southeast Asia. In Thailand, eight Pseudostrandesia species have been encountered. All of them are rare or uncommon species in the country, except for P. mamarilorum (see Savatenalinton \& Suttajit 2016), five of which are endemic to Thailand.

\section{Strandesia}

Strandesia prachuapensis sp. nov., Strandesia flavescens and Strandesia odiosa are very similar at first sight forming a closely related species complex. Hence, one could doubt the validity of the specific status of these taxa. However, their identity as separate species can be strongly supported by the additional aspects of the valves and soft parts.

Strandesia prachuapensis sp. nov. resembles $S$. flavescens and $S$. odiosa mainly in the presence of the anterior flange on the RV and the large size of Cp. Strandesia flavescens was described from Indonesia (Klie 1932) and subsequently found in India (Victor \& Fernando 1979a), and recently in South Korea (Smith et al. 2014). Strandesia odiosa was also described from Indonesia (Sulawesi - Moniez 1892) and the type materials were re-examined by Victor \& Fernando (1979b). They not only provided the redescription with some illustrations but also placed $S$. flavescens as a junior synonym of $S$. odiosa. However, Smith et al. (2014) provided some distinguishing features of these two taxa and reinstated $S$. flavescens as a valid species, based on a specimen from South Korea. This allocation was later followed by Meisch et al. (2019). Although S. prachuapensis sp. nov. shares the presence of the RV anterior flange with $S$. flavescens and $S$. odiosa, the aspect of this structure is different. In the new species, the anterior flange is narrower and does not reach the mouth region, whereas it is wide and reaches the mouth region in the two related taxa. The carapace size of the new Strandesia species (ca $1.5 \mathrm{~mm}$ ) is somewhat smaller than that of S. flavescens and S. odiosa, which have lengths of ca $2 \mathrm{~mm}$ (see Smith et al. 2014) and $2.4 \mathrm{~mm}$ (see Victor \& Fernando 1979b), respectively. In the Strandesia new species, the aspect of the LV antero-ventral part is outstanding showing more angulated, while this part is rounded in both $S$. flavescens and $S$. odiosa. The inner list on the LV anterior inner lamella is also different among these three taxa. There is no inner list in $S$. odiosa, while the obvious inner list is seen in $S$. flavescens, and a weak and small inner list existing on the antero-ventral part is recognized in $S$. prachuapensis sp. nov. 
Additionally, other distinguishing features can be observed in these three related species. Strandesia prachuapensis sp. nov. can be distinguished from S. flavescens by the more arched $\mathrm{Cp}$ in the lateral view, the absence of septa-like structures on the LV, the longer claw Ga and the shorter claw Gp. Strandesia new species differs from $S$. odiosa by the more elongated Cp, the smooth bristles on the Mx1 third endite (serrated in S. odiosa), the length of the shortest natatory seta on the A2 (longer in the new species) and the shorter f-seta on the T2. It should be noticed that the insertion of the aesthetasc $\mathrm{Y}$ on the A2 in S. prachuapensis sp. nov. is rather more proximal, situating ca one fourth of the segment, whereas in other Strandesia species, it is typically approximately mid-length on the first endopodal segment.

Strandesia prachuapensis sp. nov. also shares the presence of an anterior flange on the RV with another Southeast Asian Strandesia, S. feuerborni Klie, 1932. However, the anterior flange of S. feuerborni is considerably larger and slightly slopes downward as well as reaching the mouth region. This notable anterior flange, together with an obvious dorsal hump on the RV are the outstanding indicative characters of $S$. feuerborni, which cannot be confused with $S$. prachuapensis sp. nov.

It should be noted that, on the third and the fourth segments of the A1 in S. prachuapensis sp. nov., the ventral setae have an unusual aspect, appearing like aesthetasc-like setae (Fig 8A'). Such setae have also been obviously recognized in other cypricercine species, such as Pseudostrandesia thailandensis, Pseudostrandesia mamarilorum (see Savatenalinton \& Martens 2010), Pseudostrandesia striatoreticulata, Tanycypris siamensis Savatenalinton \& Martens, 2009 and Bradleytriebella tuberculata (Hartmann, 1964) (see Savatenalinton \& Martens 2009b). The A1 seta is known as a swimming appendage in most ostracods and bears several sensory organs/setae, e.g., Rome organ, Wouters organ and aesthetasc $\mathrm{y}_{\mathrm{a}}$. Hence, the presence of these modified setae in the Strandesia new species, including other representatives of Cypricercinae, is highly possibly related to sensory reception. The detailed morphology of the A1 setae, together with the comparison of these aesthetasc-like setae and normal setae, will be present elsewhere.

Most cypricercine species have marginal selvage on the RV while in the LV, it lies apart from the valve margin. In Cypricercinae, the anterior flange that occurs on the RV only, is a rare feature as it has been recognized in only a few species. According to the diagrams of the marginal zone structure provided by Horne \& Colin (2005), the morphology of the RV anterior flange in Strandesia is similar to that of Cypris O.F. Müller, 1776. Both taxa have an anterior flange on the RV resulting from the inwardly displaced selvage. One-hundred and one species of Strandesia have so far been recorded worldwide covering many zoogeographical regions (see Meisch et al. 2019; Ferreira et al. 2020; present study), and only eight of them, including the new species, possess an anterior flange on the $\mathrm{RV}$, which would indicate that this character is more derived. These eight species can be divided into three groups, on the basis of zoogeographical distribution, namely Oriental and Palaearctic, Afrotropical and Neotropical regions. The former group comprises four species (S. feuerborni, S. flavescens, S. odiosa and S. prachuapensis sp. nov.) while two (S. evae Gauthier, 1951 and S. hancocki (Lowndes, 1931)) and two (S. ewaldi Karanovic, 2006 and S. colombiensis Roessler, 1990) species, respectively, belong to the two latter groups. Since their fossils are unknown, their origins remain obscure.

\section{Acknowledgements}

This research was financially supported by the Thailand Research Fund (TRF, contract number DBG6180013). Prof. Dr Tadeusz Namiotko (University of Gdansk, Poland) and an anonymous reviewer provided useful comments. Apirada Manpae (MSU, Thailand) offered technical assistance with the scanning electron micrographs. Suwaree Disapirom, Taewit Disapirom and Darun Disapirom are specially thanked for their assistance with field work during the whole research project. 


\section{References}

Broodbakker N.W. \& Danielopol D.L. 1982. The chaetotaxy of Cypridacea (Crustacea, Ostracoda) limbs: proposals for a descriptive model. Bijdragen tot de Dierkunde 52 (2): 103-120. https://doi.org/10.1163/26660644-05202003

Ferreira V.G., Higuti J. \& Martens K. 2020. Taxonomic revision of Strandesia s.s. (Crustacea, Ostracoda) from four Brazilian floodplains, with the description of three new species. Zootaxa 4760 (1): 1-74. https://doi.org/10.11646/zootaxa.4760.1.1

Horne D.J. \& Colin J.-P. 2005. The affinities of the ostracod genus Cypridea Bosquet, 1852, and its allies, with consideration of implications for the phylogeny of nonmarine cypridoidean ostracods. Revue de Micropaléontologie 48: 25-35. https://doi.org/10.1016/j.revmic.2004.12.003

Klie W. 1932. Die Ostracoden der Deutschen Limnologischen Sunda-Expedition. Archiv für Hydrobiologie, Supplementband 11: 447-502.

Külköylüoğlu O., Yavuzatmaca M. \& Y1lmaz O. 2020. A new species of the genus Pseudostrandesia (Ostracoda: Crustacea) and first report of the genus from Palaearctic region. Zoology in the Middle East 66 (1): 37-45. https://doi.org/10.1080/09397140.2020.1675993

Martens K. 1987. Homology and functional morphology of the sexual dimorphism in the antenna of Sclerocypris Sars, 1924 (Crustacea, Ostracoda, Megalocypridinae). Bijdragen tot de Dierkunde 57 (2): 183-190. https://doi.org/10.1163/26660644-05702003

Meisch C. 2000. Freshwater Ostracoda of Western and Central Europe. In: Schwoerbel J. \& Zwick P. (eds) Süßwasserfauna von Mitteleuropa 8 (3): 1-522. Spektrum Akademischer Verlag, Heidelberg, Berlin.

Meisch C., Smith R.J. \& Martens K. 2019. A subjective global checklist of the extant non-marine Ostracoda (Crustacea). European Journal of Taxonomy 492: 1-135. https://doi.org/10.5852/ejt.2019.492

Moniez R. 1892. Entomostracés d'eau douce de Sumatra et de Célèbes-2: Ostracodes. In: Weber M. (ed.) Zoologische Ergebnisse einer Reise in Niederländisch Ost-Indien 2: 129-135. E.J. Brill, Leiden. Available from https://doi.org/10.5962/bhl.title.52289 [accessed 19 Jan. 2021].

Savatenalinton S. 2014. Ostracods (Crustacea: Ostracoda) from the floodplain of the Chi River, Mahasarakham Province, Northeast Thailand, with the first record of male Tanycypris siamensis Savatenalinton \& Martens, 2009. Zootaxa 3838 (2): 195-206.

https://doi.org/10.11646/zootaxa.3838.2.4

Savatenalinton S. 2015. On three new species of non-marine ostracods (Crustacea: Ostracoda) from Northeast Thailand. Zootaxa 3914 (3): 275-300. https://doi.org/10.11646/zootaxa.3914.3.3

Savatenalinton S. 2017. Species diversity of ostracods (Crustacea: Ostracoda) from rice fields in Northeast Thailand, with the description of a new Tanycypris species. Zootaxa 4362 (4): 499-516. https://doi.org/10.11646/zootaxa.4362.4.2

Savatenalinton S. \& Martens K. 2009a. Redescription of the type species of Strandesia Stuhlmann, 1888 and Cypricercus Sars, 1895 (Crustacea, Ostracoda, Cypricercinae), with a description of a new species of Cypricercus from South Africa. Zootaxa 2007: 1-42. https://doi.org/10.11646/zootaxa.2007.1.1

Savatenalinton S. \& Martens K. 2009b. Generic revision of Cypricercinae McKenzie, 1971 (Crustacea, Ostracoda), with the description of three new genera and one new species and a phylogenetic analysis of the subfamily. Hydrobiologia 632 (1): 1-48. https://doi.org/10.1007/s10750-009-9826-5

Savatenalinton S. \& Martens K. 2010. On the subfamily Cypricercinae McKenzie, 1971 (Crustacea, Ostracoda) from Thailand, with the description of six new species. Zootaxa 2379: 1-77.

https://doi.org/10.11646/zootaxa.2379.1.1 
Savatenalinton S. \& Suttajit M. 2016. A checklist of recent non-marine ostracods (Crustacea: Ostracoda) from Thailand, including descriptions of two new species. Zootaxa 4067 (1): 1-34.

https://doi.org/10.11646/zootaxa.4067.1.1

Smith R.J., Lee J. \& Chang C.Y. 2014. Nonmarine ostracoda (Crustacea) from Jeju Island, South Korea, including descriptions of two new species. Journal of Natural History 49 (1-2): 37-76.

https://doi.org/10.1080/00222933.2014.946110

Victor R. \& Fernando C.H. 1979a. The freshwater ostracods (Crustacea: Ostracoda) of India. Zoological Survey of India 74: 147-242.

Victor R. \& Fernando C.H. 1979b. On some freshwater ostracod type specimens from Indonesia. Canadian Journal of Zoology 57: 6-12. https://doi.org/10.1139/z79-002

Victor R. \& Fernando C.H. 1981. Freshwater ostracods (Crustacea: Ostracoda) of the genus Strandesia Vávra, 1895 from Malaysia, Indonesia and the Philippines. Archiv für Hydrobiologie, Suppl. 58 (4): $469-522$.

Manuscript received: 13 August 2020

Manuscript accepted: 11 November 2020

Published on: 27 January 2021

Topic editor: Rudy Jocqué

Desk editor: Pepe Fernández

Printed versions of all papers are also deposited in the libraries of the institutes that are members of the EJT consortium: Muséum national d'histoire naturelle, Paris, France; Meise Botanic Garden, Belgium; Royal Museum for Central Africa, Tervuren, Belgium; Royal Belgian Institute of Natural Sciences, Brussels, Belgium; Natural History Museum of Denmark, Copenhagen, Denmark; Naturalis Biodiversity Center, Leiden, the Netherlands; Museo Nacional de Ciencias Naturales-CSIC, Madrid, Spain; Real Jardín Botánico de Madrid CSIC, Spain; Zoological Research Museum Alexander Koenig, Bonn, Germany; National Museum, Prague, Czech Republic. 